\title{
IDENTIDADE POLÍTICA, DESIGUALDADE E PARTIDOS BRASILEIROS
}

\author{
FÁBIO WANDERLEY REIS
}

\section{RESUMO}

O artigo analisa o processo de institucionalização partidária no Brasil pós-redemocratização. A formação do Partido dos Trabalhadores, e seu repetido enfrentamento eleitoral com o PSDB, aponta para um processo em andamento mas ainda incompleto: a criação, em torno dos dois partidos, de identificações político-partidárias estáveis que podem eventualmente redundar num sistema partidário simplificado e consolidado, com, entre outras coisas, a neutralização do êxito até aqui obtido pela postura excessivamente clientelista e pragmática que orienta o fragmentário enraizamento regional do PMDB.

PALAVRAS-CHAVE: Identidades político-partidárias; desigualdade; Partido dos Trabalhadores; Partido da Social-Democracia Brasileira.

\section{ABSTRACT}

The article discusses the process of institutionalization of political parties in Brazil in the post-redemocratization period. The advent of the Worker's Party (PT), and its electoral disputes with the Brazilian Social Democracy Party (PSDB) point to an ongoing yet unaccomplished process: the emergence, in the orbit of both parties, of stable political-partidary identifications that could lead to a simplified and consolidated party system and the neutralization of the success of the excessively clientelistic and pragmatic orientation that characterizes Brazilian Democratic Movement Party's (PMDB) feeble regional roots.

KEYWORDS: Political-partidary identities; inequality; Worker's Party; Brazilian Social Democracy Party.

[1] Pizzorno, A. "Su democrazia e sfera pubblica immaginaria". Sociologica, $2008, \mathrm{n}^{\circ} 3, \mathrm{pp} \cdot 1-22$.

\section{DEMOCRACIA E IDENTIDADES POLÍTICO-PARTIDÁRIAS}

Em artigo publicado em 2008, Alessandro Pizzorno discute problemas relacionados à representação política, retomando temas a que se dedica há muito ${ }^{1}$. Ressaltando o fato de que, nas condições atuais de operação da democracia, os eleitores são cada vez mais destituídos de influência real sobre as políticas públicas, restrita amplamente a grupos de pressão, Pizzorno examina o papel de lideranças, movimentos ou partidos em termos do contraste entre os bens de curto prazo e os de longo prazo que os cidadãos podem esperar do processo político. Esse papel é descrito em termos de "oferta de esperança": em vez de um governo representativo capaz de colocar seus eleitores em condições de avaliar as vantagens ou as desvantagens de uma ou outra política pública, teríamos sistemas de partidos e unidades coletivas de tipo variado (étnicas, religiosas) em que a autoridade da classe política 
estaria fundada na combinação da esperança que oferece quanto a fins de longo prazo - em larga medida, segundo Pizzorno, imaginários: fins nacionais, de classe, da humanidade, dos povos do mundo - com a capacidade de transformar essa esperança em consenso para as políticas de curto prazo. É a relação entre a classe política e a população, afirma Pizzorno, que o Estado deve empenhar-se em tornar virtuosa; e somente a presença de doutrinas em que se expressem fins de longo prazo divergentes (o aspecto de divergência é salientado) pode dar sentido a uma participação na vida política que não seja meramente "profissional" ou clientelística, características estas associadas à busca de objetivos privados pela classe política eà idéia de uma sociedade de "caroneiros" ou aproveitadores.

Essa perspectiva se associa, no exame de problemas da democracia e da política em geral, com a ênfase na identidade. Avesso a recentes concepções da democracia de economistas que tendem a equiparar a dinâmica democrática à do mercado, Pizzorno salienta as questões de identidade como as que seriam distintivas da política. Mas as sociedades que Pizzorno tem mais diretamente diante dos olhos são sobretudo sociedades de características social-democráticas, fruto da afirmação de identidades referidas em ampla medida a interesses materiais eà "questão social", e os fins “imaginários" de longo prazo a que Pizzorno se refere incluem com destaque os relativos a classes sociais.

A abordagem de Pizzorno coloca em foco alguns dos temas que têm sido recorrentemente tomados a propósito dos partidos e de seu desenvolvimento. De um lado, temos o tradicional recurso à idéia de ideologia e à característica menos ou mais ideológica dos partidos, elaborada classicamente na distinção de Maurice Duverger entre "partidos de quadros" e "partidos de massas", estes últimos correspondendo em particular aos partidos socialistas de origem extraparlamentar baseados na militância contínua de membros filiados. Vistos por Duverger como os partidos do futuro, os partidos de massas ideológicos fornecem a referência latente de um modelo geral de "política ideológica" que segue prevalecendo amplamente, no Brasil como em outros países, e no qual se supõe que partidos e eleitores se distribuam com clareza ao longo de um eixo esquerda-direita. Em contraposição, revisões já não tão recentes têm apontado a tendência, que resultaria fatalmente do mero envolvimento no jogo eleitoral e do imperativo de diluir a mensagem para conquistar maiorias, de que os partidos se transformem em "partidos pega-tudo" (catch-all parties), modificando de maneira mais ou menos acelerada suas relações tanto com as "bases" quanto com o próprio Estado (eventualmente dando origem ao que alguns chamaram "partidos-cartel", em que o acesso às benesses do Estado acaba compartilhado em algum grau entre os diversos partidos). De todo modo, tal evolução acabaria por ensejar a 
prevalência de um pragmatismo afim aos partidos de quadros, que se faria acompanhar, em termos de psicologia política, de um clima de "cultura cívica" em que a adesão generalizada aos valores comuns da coletividade abrangente (nacional) e a identificação com ela permitiriam que arrefecessem os antagonismos políticos e,em conseqüência, o estímulo ao envolvimento com a política.

A esse respeito, o interesse da perspectiva trazida por Pizzorno consiste em que, em vez de identificações divergentes ou antagônicas se contraporem a composições pragmáticas, recupera-se a complexidade sempre presente no jogo político de interesses que se agregam e hostilizam. Por "imaginários" que sejam os fins de longo prazo propostos, eles são efetivos em produzir identificação e identidades político-partidárias. E mesmo seestas se mostram instrumentais para a produção de consensos pragmáticos quanto ao curto prazo, respaldando composições protagonizadas pelos partidos, o componente de antagonismo contido na identificação partidária e na mobilização em torno de fins ambiciosos é também condição para que a relação entre a classe política e a população possa adquirir o caráter virtuoso mencionado, em vez de acabar substituída por um aguado "civismo" negativamente marcado por "profissionalismo" e clientelismo políticos.

Por outro lado, a ênfase em questões de identidade, tomada do ponto de vista da experiência das sociedades social-democráticas e de problemas de estratificação social, permite destacar algo especial. Genericamente, identidade tem a ver com relações de igualdade e diferença, que dizem respeito à diversidade de etnias, culturas e nacionalidades, em sentido amplo, assim como tem a ver com o caso específico de relações hierárquicas entre classes sociais ou categorias sociais estratificadas de qualquer tipo - que correspondem antes a relações de igualdade e desigualdade. Em outras palavras, a relação igual-desigual é um caso particular da relação igual-diferente. Contudo, são as relações de igualdade e desigualdade, ou de poder social desigual, que se revelam crucialmente relevantes do ponto de vista do tema geral da democracia, e as diferenças étnicas ou culturais só interessam, deste ponto de vista, na medida em que tendem a associar-se com domínio e subordinação.

\section{DIFERENÇAS, DESIGUALDADES E INSTITUCIONALIZAÇÃO POLÍTICA NO BRASIL}

A implantação e o desenvolvimento do Estado nacional moderno envolveu com freqüência problemas de "assimilação", em que se tratava justamente de dar solução ao problema da "identidade nacional", com a neutralização da importância de eventuais diferenças étnicas ou culturais, criando-se assim o substrato sociopsicológico apropriado à afirmação da aparelhagem burocrática do Estado sobre 
as coletividades "nacionais" envolvidas. Na verdade, na Europa (e não só lá) tais problemas seguem bem vivos até hoje: com a derrocada do comunismo, a fragmentação ocorrida na Europa oriental reeditou e intensificou, às vezes de forma trágica, o processo de "balcanização", enquanto os próprios avanços integradores da União Européia (e da globalização, mais amplamente) favoreceram, em vários países da Europa ocidental, movimentos de autonomia regional que envolviam ou envolvem diferenças étnico-lingüísticas e especificidades culturais, ou "nacionalidades" menos ou mais reais.

Mas é a questão social, assentada na diferença como desigualdade, que marca a dinâmica da implantação e do desenvolvimento da democracia. Essa proposição é verdadeira mesmo se recuamos do mundo moderno para a Antiguidade clássica. A experiência da democracia ateniense teve seu traço distintivo, e o duradou ro foco de conflito que terminou por comprometê-la, na figura do cidadãocamponês, na qual Ellen Meiksins Wood (nos ensaios de Democracy against capitalism ${ }^{2}$ ) sintetiza a idéia de que os "produtores" ou trabalhadores manuais (camponeses, sapateiros, ferreiros) podiam ser governantes, podiam ser cidadãos e como cidadãos participar do governo da comunidade - idéia esta que, como elabora Wood, veio a ser o grande cavalo de batalha nas discussões sobre a democracia ateniense nas obras dos pensadores clássicos da própria Atenas, que em geral se opunham fortemente a ela.

É no mundo capitalista do pós-Renascimento, contudo, que a questão social adquire relevância definitiva. A afirmação liberal da igualdade perante a lei e dos direitos civis radicaliza-se na reivindicação dos direitos político-eleitorais, que se desdobra na busca da igualdade de maior alcance, da redistribuição e dos direitos sociais. Em vários países, essa busca, apesar de trazer a questão social para o cerne das disputas eleitorais, conformou as experiências social-democráticas em que arrefeceu o radicalismo socialista dos casos mais exemplares de partidos ideológicos de massas.

Mas as vicissitudes das lutas sociais têm também um resultado de feições distintas, que vem a ser de grande importância para a dinâmica política e partidária no Brasil:a confrontação em nível planetário entre capitalismo e socialismo na Guerra Fria, que marcou longamente a segunda metade do século XX. Um aspecto saliente do quadro assim criado é o de que os enfrentamentos domésticos que ocorrem em cada país, especialmente na periferia do sistema mundial, se aguçam ao se transformarem em episódios do enfrentamento internacional entre os dois campos. No Brasil, isso tem o efeito de intensificar algo que vinha de longe: o protagonismo político dos militares (o "pretorianismo", na expressão de alguns) como parte crucial da debilidade do enquadramento institucional do jogo político. A implantação, em 1964, da
[2] Cambridge/Nova York, Cambridge University Press, 1995 . 
[3] Finley, M. I. Ancient slavery and modern ideology. Nova York: Viking Press, 1980 .
[4] Tenho evocado a respeito um editorial d'O Estado de São Paulo de $1^{\circ}$ de janeiro de 1901, republicado pelo jornal em 31 de dezembro de 1999, a propósito da virada do século XX para o XXI, e cujo interesse consiste na candura com que transparecem o eurocentrismo e o racismo da elite brasileira do imediato pós-escravismo.A imagem do Brasil que o editorial deixa entreveréa de um país europeu que acontecia ter recorrido às conveniências da mão-de-obra escrava africana - e agora a via transformada num problema. ditadura militar que viria a durar 21 anos é o coroamento desse processo. Ela acontece num momento em que a grande desigualdade herdada de nossa longa experiência escravista se combina tumultuadamente com a transformação econômico-social, o crescimento das cidades e das massas populares urbanas e a enorme expansão do eleitorado.

Os elementos de transformação e novidade nesse quadro têm, naturalmente, grande importância na explicação das turbulências que culminamem 1964. Mas o entendimento mais adequado da complexa atualidade política brasileira e das deficiências institucionais que permanecem, mesmo superada a ditadura, exige que se ressalte o papel cumprido pelo que há de viscoso e resiliente no legado de nossa história mais remota.

O ponto crucial são os efeitos da multissecular experiência escravista recém mencionada, da qual, naturalmente, todos temos conhecimento, mas de cujo impacto profundo freqüentemente não tomamos consciência adequada. Ela singulariza o Brasil de modo especial: não só nos incluímos entre os poucos casos, em toda a história, de sociedades propriamente "escravagistas" (que Finley 3 caracteriza pelo recurso em grande escala ao trabalho escravo tanto no campo como nas cidades e que, na listagem de Ellen M. Wood, são a Atenas clássica, a Itália romana, as ilhas das Índias Ocidentais, o sul dos Estados Unidos e o Brasil), mas somos também o único país moderno de dimensões significativas a contar com um legado escravista maciço — nos Estados Unidos, afinal, a escravidão perdeu a guerra.

A conseqüência, que se pode resumir na singular e persistente desigualdade brasileira, é que as carências materiais em que a longa escravidão se traduz para grande parcela dos estratos populares do país têm contrapartida decisiva no plano da psicologia coletiva e de suas projeções políticas. Um aspecto merece destaque: na sociedade de castas que a escravidão construiu (demarcadas, ademais, por traços físicos de alta visibilidade), a população de origem africana não chegava sequer, durante muito tempo, a ser percebida como fazendo realmente parte do povo brasileiro 4 , o que é certamente a explicação última de nossos investimentos insuficientes em educação e da precariedade do sistema educacional brasileiro até hoje (educar "essa gente"?). Essa deficiência é um correlato importante do quadro psicológico produzido, em que o longo jogo político oligárquico e seus mecanismos clientelísticos combinavam a perspectiva aristocratizante da elite com a passividade e o conformismo próprios, na sociedade de castas, das camadas menos favorecidas. Aos olhos destas, a desigualdade tende a aparecer como parte da ordem natural das coisas e a não ser vivida como problema efetivo: não se manifesta subjetivamente de forma a dar lugar ao sentimento de injustiça e à conseqüente disposição afirmativa e reivindicante. 
Naturalmente, as transformações estrutural-ecológicas e comunicacionais das décadas recentes não poderiam deixar de impactar também o plano da psicologia coletiva, gerando mecanismos de comparação e frustração há muito estudados pela sociologia como fonte do sentimento de injustiça e fator de instabilidade - e dando razão, em termos psicológicos e não apenas "objetivos", à observação de Fernando Henrique Cardoso, quando presidente da República, de que o Brasil não seria mais um país subdesenvolvido, e sim um país injusto. Mas, apesar da incorporação eleitoral que acaba por mostrar-se inelutável nas condições do difuso apoio convencional à democracia na atualidade mundial, as deficiências de todo tipo perpetuadas pelo resistente fosso social brasileiro condicionam de modo relevante os efeitos do processo geral na esfera política e partidária.

Assim, parte importante da insatisfação popular, em vez de encontrar canalização político-institucional apropriada, pode servir simplesmente de combustível na intensificação acentuada da violência e da criminalidade comum. Mesmo nas suas manifestações políticopartidárias, contudo, é evidente que o idealizado modelo de "política ideológica” dificilmente poderia ser visto como ajustando-se, em particular, aos mecanismos populistas que há muito operam no processo político do país.

\section{PMDB, PSDB E PT}

De todo modo, as deficiências de nosso substrato social desigual se traduzem também em claras deficiências no processo de construção partidária, quando apreciado do ponto de vista do modelo de política ideológica. É certo, não deixamos de encontrar a percepção, por parte do establishment, de ameaças próprias da política ideológica a surgirem no plano da dinâmica partidária, como ocorreu, num quadro de radicalização que se intensificava, com o crescimento gradual do apoio eleitoral ao PTB de Getúlio Vargas durante o período de 1945 a 1964.A ditadura militar de 1964 tratou de agir contra as ameaças percebidas, especialmente com a dissolução dos partidos daquele período e sua substituição pelo bipartidarismo imposto de Arena e MDB. A iniciativa, contudo, revelou-se um erro de cálculo. Sua conseqüência foi que a simplificação das opções eleitorais se ajustasse bem aos simplismos da visão política das parcelas populares majoritárias do eleitorado característica do populismo - e, ao contrário do esperado pelos mentores do regime militar, favorecesse o partido de oposição, o MDB, a partir do momento em que as vicissitudes do regime lhe permitiram transmitir, em 1974, uma mensagem afirmativa de feição popular.

As manobras seguintes do regime, como se sabe, ensejaram novas mudanças do quadro partidário, em que se esfacelou o singular recur- 
so eleitoral que o MDB chegou a representar. Tais mudanças atingiram seu ápice já bem mais tarde, em 1988, quando se dividiu o PMDB, herdeiro direto do MDB, com a criação do PSDB. Mas o quadro geral alterado permitiu o que foi, sem dúvida, a grande novidade na história partidária brasileira, o aparecimento do PT. A novidade consistiu na combinação inédita que o partido conseguiu realizar de dois traços: de um lado, como conseqüência da gradual afirmação da forte liderança sindical de Lula e do poder catalisador que veio a ter junto a outros setores comprometidos com idéias progressistas, nos movimentos sociais e na Igreja, o partido veio a representar singular promessa de atuação orientada por princípios éticos e ideológicos (em particular certo compromisso redistributivo), capaz de conjugar militância aguerrida com disciplina partidária; de outro lado, o simbolismo popular difuso ligado à figura de Lula trazia um elemento propício à inserção bemsucedida no jogo eleitoral, com seu inevitável componente populista nas condições gerais do Brasil.

As modificações dramáticas no cenário internacional acarretadas pela derrocada mundial do socialismo tornaram possível que a atração pessoal exercida por Lula e a militância aguerrida do PT viessem a ensejar um experimento impensável no quadro anterior de Guerra Fria: a chegada à presidência da República, em 2002, do líder operário de um partido de esquerda, de programa socializante e retórica radical.

Não obstante os temores inicialmente suscitados no establishment, que cercaram a eleição daquele ano da ameaça de crise catastrófica, esse evento acabou por representar uma oportunidade singular de aprendizado geral e um teste decisivo para a democracia brasileira, permitindo seu acesso a um novo patamar institucional. Parte importante do aprendizado realizado foi o de moderação e equilíbrio por parte de Lula e do PT, substituindo as propostas socialistas originais por políticas sociais de orientação social-democrática conjugadas com a continuidade de políticas econômico-financeiras austeras. As origens ideológicas do PT levaram, à esquerda, não só a cobranças baseadas na visão equivocada de que, com a moderação ocorrida, não teríamos tido um teste autêntico de nossa democracia (que dependeria, nessa ótica, da aposta obviamente precária de que a democracia viesse a ser o enquadramento institucional de um governo propriamente revolucionário - e sobrevivesse a ele...); tais origens estão também claramente subjacentes à arrogância ideológica que se transvestiu no tosco "realismo" da compra de apoio parlamentar desvendado na grande crise de 2005, na qual a própria imagem de apego a princípios e compromisso ético do partido se viu comprometida.

As dificuldades daí resultantes colocaram em xeque o processo inédito de construção institucional na faixa partidária que a mescla petista parecia envolver. Seguiu-se o afastamento, em grau importan- 
te, entre o partido como tal, submetido a cisões e defecções, e liderança pessoal de Lula, que, tendo tido certamente seu pior momento na crise de 2005, terminou por reeleger-se com grande votação para um segundo mandato e por alcançar altíssimos níveis de popularidade na esteira dos êxitos da política social e econômica. Tais êxitos culminam mesmo na súbita elevação do status do país na cena mundial, impulsionada pela dinâmica econômica propícia já de há algum tempo, mas sem dúvida incorporando a imagem de Lula como fator coadjuvante.

\section{DEMOCRACIA E REDISTRIBUIC̄̃̃O: BRASIL E AMÉRICA LATINA}

Dois aspectos podem ser destacados como especialmente significativos nessa situação. O primeiro é o mencionado fortalecimento institucional da democracia brasileira. Dificilmente se poderia exagerar, mesmo pondo de lado os êxitos indicados, a importância de uma presidência PT/Lula que chega ao fim do segundo mandato num quadro de normalidade institucional. Naturalmente, dado o nosso longo pretorianismo e o protagonismo há muito exercido pelas forças armadas, a questão decisiva é aqui a da "domesticação" institucional dos militares e de até que ponto ela se terá cumprido cabalmente. Acabamos de ter, com a retomada da discussão em torno da Lei de Anistia de 1979 a propósito do III Programa Nacional de Direitos Humanos e o empenho do governo em aplacar a insatisfação exibida por chefes militares, clara indicação de que o assunto não se encontra inteiramente resolvido. Contudo, mesmo se o trato com os militares persiste como algo delicado para o governo em circunstâncias em que a memória dos pesados custos da longa ditadura de 1964 ainda está bem viva, nada parece justificar a idéia de que tenhamos uma "crise militar" efetiva, ou temores análogos aos que marcavam com freqüência o período pretoriano de nossa história recente: não há como cogitar a sério de golpe militar, e a definitiva inserção democrática das forças armadas no quadro político-institucional brasileiro, com a superação do "complexo de sublevação" que elas compartilhavam com outros setores de nossas elites, parece não ser senão questão de tempo.

Seja como for, temos aqui algo que subsiste como relevante nos embates da atual cena política brasileira, dizendo respeito a como lidar com a memória da ditadura e, em particular, com o tema da anistia e dos esforços de certos setores para obter a revisão judicial da lei correspondente e, assim, possibilitar a punição dos envolvidos nos crimes da repressão, especialmente a tortura. A questão principal que o problema encerra é o equilíbrio a ser alcançado entre o apego a um realismo necessário à superação dos conflitos que produziram a ditadura $e$ se aguçaram com ela, de um lado, e, de outro, o empenho normativo de fazer justiça. Como elaborado por alguns, especialmente Paulo Bros- 
sard em artigo de jornal que circulou no início de 2010 na internet ("Anistia é irreversível"), o objetivo da anistia, em vez de fazer justiça, foi o de pacificar o país, criando condições propícias à implantação eà eventual consolidação da democracia. Essa perspectiva é convergente com análises de cientistas sociais sobre o processo de transição à democracia na América Latina e em outras partes, que recomendavam o reconhecimento realista das assimetrias de poder e destacavam, em especial, a necessidade de acomodar os interesses da corporação militar como forma de tornar a transição efetivamente possível.

No debate corrente sobre a Lei de Anistia, porém, esse ânimo realista tem sido substituído, nos setores de opinião de esquerda, pelo problemático apelo à contraposição entre "crime político" e "crime comum", em que a idéia de crime político acaba por legitimar as ações daqueles que, por terem na cabeça certa idéia que presumem permitir organizar melhor o Estado e a sociedade, se sentem autorizados a recorrer à violência. Apesar da tendência da imprensa a tratar às vezes as vítimas da ditadura como "opositores do regime que pegaram em armas", é claro que a ditadura, com seus crimes inequívocos e hediondos, se confrontou também com uma cultura de violência que havia tempos vinha se difundindo, marcada pela romântica aceitação da violência em nome de objetivos políticos supostamente nobres (uma última violência para por fim à violência sistêmica...), sob a influência de idéias marxistas ou por motivos de inspiração até diretamente religiosa. Mas pode-se ver também o realismo a operar em surdina, por assim dizer, mesmo na posição ansiosa por fazer justiça. Pois a disposição de caça aos torturadores que subsiste faz vista grossa para o fato de que eles eram, afinal, "pau mandado" dos chefes maiores do regime ditatorial, que não se procurou levar ao banco dos réus. O que acaba convergindo com a hipocrisia contida na famosa manifestação em que Pedro Aleixo, opondo-se ao Ato Institucional n ${ }^{\circ} 5$ mas evitando enfrentar-se com os chefes militares, declarava que o motivo de preocupação eram as arbitrariedades que viriam não do presidente da República, mas do guarda da esquina.

Como quer que seja, não obstante as reservas que talvez se justifiquem quanto à timidez da justiça brasileira sob a ditadura, cabe ver com bons olhos, em perspectiva mais ampla sobre a dinâmica política do país, as decisões do Judiciário que têm preservado a simetria pacificadora da Lei de Anistia - ainda que cumpra reconhecer, sem dúvida, que os fatos do sombrio período ditatorial de nossa história recente devem ser desvendados e trazidos ao conhecimento de todos.

Quanto ao segundo aspecto significativo acima anunciado com respeito ao panorama político atual, ele se refere à nova forma adquirida pela presença da "questão social" no processo político-eleitoral do Brasil. Naturalmente, a questão social se faz presente há tempos, 
desde que o fosso social herdado da escravidão começou a combinarse com a mudança social, a concentração da população nas cidades e o grande crescimento do eleitorado. Durante muito tempo, porém, o resultado dessas mudanças em termos político-eleitorais foi a forma "clássica" de populismo, caracterizada, como nas análises de Torcuato di Tella, pelo apelo ao "povão" por parte de lideranças de elite e contendo claro componente fraudulento, que se integrava como contraponto no quadro geral de instituições frágeis e pretorianismo.

Agora, é talvez possível continuar a falar de "populismo", ou ver o caso de Lula como parte de uma nova onda populista na América Latina, que alguns identificam em casos como o dos Kirchner, na Argentina, e os de Hugo Chávez (Venezuela), Evo Morales (Bolívia) e Rafael Correa (Equador). Mas é problemático separar aquilo que justifique a carga negativa da idéia de populismo, de um lado, e, de outro, a simples operação da democracia num contexto de desigualdade e de massas material e educacionalmente carentes. $O$ que temos visto, no Brasil e em países como Bolívia, Venezuela e Equador, marcados estes últimos por turbulências recentes, tende a corroborar algo que a sociologia política vem salientando de novo com força: se a democracia chega a operar de modo a incorporar as maiorias populacionais, ela se torna fatalmente redistributiva. Os dados mostram redistribuição efetiva nos países em questão, o Brasil incluído (e surpreendentemente, como têm revelado as pesquisas do Latinobarômetro, com apoio crescente à democracia nos três países vizinhos, não obstante as turbulências). Em nosso caso, de todo modo, o lulismo, combinando simbolismo popular e empenho redistributivo, resultou em algo inédito nas disputas presidenciais, tendendo a caracterizar o processo eleitoral de maneira mais geral: a intensa correlação, que transpareceu com nitidez especial na eleição de 2006, entre o apoio eleitoral a um candidato ou outro e a posição socioeconômica dos eleitores - com as projeções regionais dessa correlação. Não é casual, naturalmente, que o tema da política social se tenha imposto de forma saliente na campanha daquele ano, e prometa continuar a ser um tema de decisiva relevância nas disputas futuras.

\section{UM ÚNICO CENTRO SOCIAL-DEMOCRATA?}

As coisas são incertas, porém, quanto ao aspecto da eventual institucionalização partidária. A alternativa realisticamente concebível ao modelo idealizado de "política ideológica" que tem predominado entre nós é a de um sistema partidário em que a percepção desinformada e difusa dos interesses em jogo permita, mesmo se influenciada por fatores personalistas e "espúrios" do ponto de vista daquele modelo, a identificação estável com alguns partidos, podendo assim servir de 
suporte a políticas orientadas por perspectiva de longo prazo. Pesquisas sobre identificação partidária no Brasil têm mostrado que ela não ocorre senão numa minoria do eleitorado (cerca de 35\% dele em 2002), incluindo proporção apreciável da minoria sofisticada e politicamente atenta. Isso pode ser comparado, por exemplo, com números relativos aos Estados Unidos: informações do portal Rasmussen Reports de meados de 2009 mostravam que 36,8\% dos adultos estadunidenses se consideravam democratas e 33,3\% se diziam republicanos; sem embargo das oscilações nas proporções de identificados com um partido ou outro ou de "independentes", o total de identificados gira há anos, naquele país, em torno dos $70 \%$.

Por outra parte, pesquisas sistemáticas revelam com abundância os matizes envolvidos nas relações entre as identificações partidárias, de um lado, e os debates programáticos ou as posições a serem adotadas em circunstâncias diversas, de outro. Já o caso clássico dos partidos socialistas originalmente revolucionários é instrutivo, pois a solução representada pelo partido para o problema da identidade pessoal de seus membros acaba por preponderar sobre os objetivos "instrumentais" da ideologia revolucionária e por dar a esta última uma feição ritualística que permite a convivência pragmática com o capitalismo. Mas pesquisas experimentais recentes nos Estados Unidos mostram, na verdade, o componente propriamente "irracional" das identificações partidárias. Elas revelam, por exemplo, que as pessoas identificadas com um dos dois grandes partidos tenderão a perceber suas próprias posições sobre um assunto como sendo expressas pelo candidato de seu partido mesmo quando ele se opõe a ela sem ambigüidades e o candidato do outro partido tem posições inequivocamente mais próximas; ou que as simpatias ou antipatias ditadas pela identificação partidária fazem que os efeitos de informação deliberadamente falsa sobre figuras ligadas a um partido ou outro persistam, na avaliação das pessoas, mesmo depois de desvendada com toda a clareza sua falsidade.

Mas velhos dados de pesquisas brasileiras referidos ao confronto entre MDB e Arena durante o regime autoritário de 1964 são também de interesse, mostrando com nitidez, na simplicidade artificial do bipartidarismo imposto, os limites de considerações programáticas relativas a questões diversas, e dando até a aparência de banalidade às constatações permitidas. Assim, nos casos em que as pessoas, de maior ou menor informação, declaravam identificar-se com um partido ou outro, a congruência ou a incongruência percebida por elas entre as suas posições pessoais e as dos partidos sobre os temas supostamente "quentes" do momento era quase inteiramente irrelevante no condicionamento de sua decisão de voto. Quer atribuíssem à Arena, por exemplo, posição contrária ou a favor de eleições populares diretas 
para os cargos políticos, quer tal posição correspondesse ou não à que declaravam ser a sua própria, quer simplesmente desconhecessem a posição do partido a respeito, os eleitores estudados concentravam maciçamente seus votos no partido de sua preferência, fosse MDB ou Arena - e só entre os que não declaravam identificação com algum dos partidos é que temas diversos produziam dispersão no voto.

Tudo isso deixa ver a força da identificação partidária, que conforma vigorosamente - ao ponto da irracionalidade — as disposições políticas em contextos diferenciados. Mas o que sugerem os dados brasileiros citados é talvez especial. Se nos outros casos se pode falar de longa efervescência ideológica em torno de partidos socialistas ou da atual "guerra cultural" nos Estados Unidos, de que os partidos têm sido atores destacados, no caso de Arena e MDB trata-se de mero artifício “institucional" recém-inventado por uma ditadura. E a sugestão é de que é fácil, de certo modo, produzir a identificação partidária e seus efeitos: basta que o sistema partidário se superponha "adequadamente" (como providenciaram inadvertidamente os ditadores) ao fosso social do país e à simplicidade com que surge na consciência popular.

A grande pergunta a respeito da eventual consolidação de nosso sistema partidário é a de se e quando virá a produzir-se a identificação partidária estável na massa dos eleitores menos envolvidos politicamente (os cerca de $65 \%$ não identificados que indicavam as pesquisas de 2002), independentemente do caráter menos ou mais sofisticado ou "ideológico" dessa identificação. Condição crucial para isso seria a estabilidade da "oferta" partidária, que tem sido impedida nas tropelias de nossa história política.

Em termos da perspectiva proposta por Pizzorno, esboçada no início deste artigo, o caso brasileiro envolve especificidades significativas. Questões de igual-diferente relativas ao enfrentamento de etnias e culturas jamais tiveram presença relevante na vida política do país. Não obstante a importância das características raciais como fator de estratificação social, diferenças raciais como tal, à parte os equívocos de certo movimento negro brasileiro, não são necessariamente o fundamento de diferenças culturais e étnicas. De toda forma, as identidades politicamente relevantes são claramente, em nosso caso, as relativas a questões de igual-desigual.E, no jogo entre os fatores mobilizadores e desmobilizadores do legado escravista e de sua superação na dinâmica socioeconômica, a indagação é se viremos a ter o jogo político democrático marcado pela convivência sadia que Pizzorno aponta entre, de um lado, a divergência, como estímulo necessário à participação e à política virtuosa que vá além do "profissionalismo" político negativo, do clientelismo e da mera busca do ganho privado, e, de outro lado, a possibilidade de construção pragmática de consenso nas sucessivas esquinas da conjuntura em que sempre vivemos. 
É de se esperar que a estabilidade institucional básica que aparentemente alcançamos, com a superação da feição mais abertamente pretoriana do processo político (mesmo se a superação real do fosso social continua a exigir larga perspectiva de tempo), venha a permitiro avanço quanto à institucionalização partidária nos termos modestos sugeridos quanto à natureza das identificações partidárias. O último par de décadas pareceu corroborar a expectativa: o que a experiência do PT teve de singular se conjugou com o repetido enfrentamento eleitoral com o PSDB, de forma a sugerir que se viessem a criar em torno dos dois partidos as identificações estáveis que eventualmente redundassem num sistema partidário simplificado e consolidado, com, entre outras coisas, a neutralização do êxito até aqui obtido pela postura excessivamente clientelista e pragmática que orienta o fragmentário enraizamento regional do PMDB. Mas, se a crise petista ensejou queo PT acabasse, em ampla medida, cedendo o passo ao lulismo, ela resultou também, ironicamente, em crise do PSDB: sucessivas derrotas em eleições para a presidência, certo vezo oligárquico da dinâmica interna que transforma a escolha de candidatos presidenciais em ameaça à coesão partidária, falha em encontrar o discurso alternativo a um lulismo inflado por avassalador apoio popular, o que impele o candidato pessedebista a presidente na eleição de 2010, José Serra, a pouco menos do que se declarar ele próprio lulista... E o êxito no enquadramento partidário de nossa democracia parece requerer que venhamos a ter novidades significativas em relação ao cenário atual.

Há nesse cenário, contudo, aspectos que podem talvez ser apreciados de maneira mais positiva. Um deles, que tem sido salientado na imprensa,é o de que o PSDB, apesar da dificuldade de opor-se com eficácia ao lulismo, mantém a perspectiva de continuar a controlar governos estaduais importantes, e mesmo a hipótese de derrota do partido na disputa presidencial de 2010 não tem por que ser lida como redundando em desastre irremediável para ele. Por outro lado, não obstante os sérios percalços da experiência do PT como partido peculiar entre nós e as reservas que o personalismo da liderança de Lula possa justificar, a força mesma adquirida pelo lulismo, em sua conexão com a penetração do processo político-eleitoral pela questão social, pode ser avaliada como ajudando a trazer uma feição social-democrática à arena em que deverão desdobrar-se os principais enfrentamentos político-partidários no país. A ampla união de forças progressistas no MDB durante a ditadura e a força eleitoral daí resultante para o partido sugerem a possibilidade teórica de uma espécie de grande MDB social-democrático.Seesse caminho se mostrou pouco viável, e se surge mesmo como indesejável na perspectiva de uma dose saudável de divergência, é com certeza positivo que, sucedendo-se à instabilidade associada com extremismos e com a confrontação de posições radica- 
lizadas, venha talvez a ser possível encontrar as condições da estabilidade institucional, como nas experiências especialmente européias do pós-Segunda Guerra Mundial, num espaço de disputas definido em termos social-democráticos. Ele se ajusta não só à proposta que deu o próprio nome ao Partido da Social-Democracia Brasileira, mas também à posição para a qual o duro aprendizado do PT eleitoralmente vitorioso e no exercício do governo o fez refluir.

\section{REFORMA POLÍTICA}

A questão geral das perspectivas de estabilidade político-institucional leva ao tema da reforma política, que se associa, em seu caráter recorrente, ao da corrupção em suas faces variadas. Sucintamente, cabe destacar duas proposições a respeito.

A primeira refere-se ao papel das normas e a sua dupla feição, quer como componentes culturais de um contexto viscoso e resiliente (o que tenho chamado "o institucional como contexto"), quer como objetos passíveis de manipulação deliberada no nível da aparelhagem institucional-legal ("o institucional como objeto"). Em vez da postura edificante que conta com uma espécie de apropriada "conversão" coletiva, não podemos esperar ser eficazes em prazos relevantes senão na ação dirigida ao institucional como objeto — ou seja, na elaboração e na implementação rigorosa de leis que alterem as expectativas dos atores e lhes afetem o cálculo. A aposta é a de que assim possamos eventualmente ver cumprir-se o preceito sociológico segundo o qual expectativas que se reiteram e corroboram acabam por transformar-se em prescrições ou normas, com a eventual mudança em direção propícia da cultura mesma e do contexto que representa. Naturalmente, as chances de que os fatos corroborem as expectativas propícias aumentam com a divergência de que fala Pizzorno e com a convivência vigilante de identidades partidárias em confronto. Do ponto de vista específico da reforma política, de todo modo, penso que, contra o convite à passividade que encontramos em certos analistas, cabe extrair do realismo da aposta no condicionamento do cálculo dos agentes e de suas expectativas o ânimo de experimentar com dispositivos legais como os relativos a fidelidade partidária, cláusulas de barreira, regras sobre coligações, adequada combinação de princípios majoritários e proporcionais, listas partidárias fechadas ou "flexíveis"...

Asegunda proposição vincula a perspectiva empenhada na reforma a certo diagnóstico da natureza da "crise ética" que estaríamos vivendo no momento, com a intensa corrupção política. Esse diagnóstico vê a intensificação da corrupção como conseqüência da democratização do país:cento e trinta milhões de eleitores num Brasil desigual significam peso político decisivo para os "menos iguais" e, supõe-se, correspon- 
dente deterioração intelectual e ética na qualidade da representação política. Mas, à parte as muitas fantasias sobre a qualidade intelectual eética de nossa velha representação oligárquica,é clara a distorção envolvida em omitir, a propósito dos nossos problemas ético-políticos de hoje, a longa tradição de estado cartorial, clientelismo e quejandos que vicejava como parte da política oligárquica (e cujos mecanismos subsistem e moldam de muitas formas o presente) e destacar, ao revés, a democratização que solapa essa política justamente ao criar potenciais focos divergentes de identificação e mobilização que gradualmente se atualizam. O elitismo do diagnóstico é desatento aos pesados traços estruturais negativos do nosso ponto de partida e aos difíceis constrangimentos que este segue impondo ao jogo político como conduto inevitável de possíveis avanços.

Um último ponto. Avaliações recentes da conjuntura política brasileira têm salientado a feição de "Estado-amálgama" que caracterizaria o governo Lula, no qual um Estado ativo trata de envolver as forças variadas da "sociedade civil" e supostamente lhes compromete a autonomia. Mas, nas condições do nosso fosso social e de precárias tradições institucionais, é patente o risco de que o jogo que se decidisse no nível da sociedade civil como tal redundasse, como sempre, em transpor sem mais para o plano das políticas do Estado as assimetrias profundas que a caracterizam. Em outras palavras, não há como escapar de dose importante de paternalismo como traço distintivo do Estado democrático, que não será aquele forçado a limitar-se a responder à capacidade diferencial de pressão de interesses de poder desigual. Ora, como os êxitos da social-democracia "neocorporativa" demonstraram - apesar das vacilações produzidas pela onda recente de fundamentalismo de mercado, já agora em retirada diante de crises cada vez maiores -, esse traço se liga com a necessária acomodação dos interesses diversos pela ação do Estado, ou mesmo, em alguma medida, no âmbito do próprio Estado. Note-se que, no caso brasileiro, a desigualdade se reflete, à parte a tese da "perda de qualidade" da representação, na extração social dos membros do próprio Legislativo, não obstante sua escolha por meio de eleições - assim como se reflete, em surdina mas de modo bem claro, no funcionamento de um Judiciário composto por membros doutos, que supostamente decidirão imparcial e isentamente com base na lei. Cumpre talvez procurar assegurar que nosso processo eleitoral traga mais nitidamente a característica de "amálgama" socialmente integrador ao Legislativo, que possa assim agir com eficiência de forma a neutralizar certo ativismo frequentemente torto do Judiciário a que nos vimos habituando. 